\title{
Growth and endocrine function after renal transplantation
}

\author{
L REES, S A GREENE, P ADLARD, * J JONES, * G B HAYCOCK, S P A RIGDEN, \\ M PREECE, ${ }^{*}$ AND C CHANTLER
}

Evelina Children's Hospital, United Medical and Dental Schools, Guy's Hospital and *Department of Growth and Development, Institute of Child Health, London

SUMmARY Longitudinal height data and physical development were assessed in 45 boys and 34 girls after renal transplantation. All children received alternate day steroids and either azathioprine or cyclosporin A for immunosuppression. There was a significant increase in growth velocity after transplantation in prepubertal children. Growth velocity declined at the expected age of the normal pubertal growth spurt, however, with delay in the appearance of secondary sexual characteristics. Overnight hormone profiles in 17 adolescent subjects with short stature or maturational delay, or both, showed blunting of growth hormone and gonadotrophin pulsatility. It is likely that long term steroid treatment after renal transplantation induces the clinical and endocrine picture of delayed puberty. Failure of growth to accelerate at this time is a cause of short stature, which may have an effect on adult height.

Growth failure is an important consequence of chronic renal failure for many children. Mean adult height is reduced on average by two standard deviations for those transplanted before the age of 15 years. Delayed puberty is also a common finding; half the girls and one third of boys reach sexual maturity later than $95 \%$ of the normal population. ${ }^{1}$ After renal transplantation many children have an appreciable improvement in their growth. Our impression, however, was that the initial increased growth rate was not sustained during the ensuing years of immunosuppressive treatment.

In boys taking long term steroid treatment for steroid sensitive nephrotic syndrome, we observed a clinical picture of delayed puberty, with blunting of the secretion of growth hormone and gonadotrophins. Immunosuppression with steroid treatment may, therefore, cause a decline in growth velocity at the time of the expected pubertal growth spurt ${ }^{2}$ and account for the lack of continuing growth improvement after renal transplantation.

We analysed retrospectively the growth and pubertal development of our current population of children and adolescents with renal transplants. We also investigated the endocrine function of 17 of the adolescents who had growth retardation or pubertal delay, or both.

\section{Patients and methods}

All children attending Guy's Hospital paediatric renal transplant clinic at the end of May 1987, and who had had a functioning graft for at least a year, were included in the study ( 45 boys, 34 girls). The causes of chronic renal failure were: obstructive uropathy $(n=18,24 \%)$, dysplasia $(n=13,16 \%)$, focal segmental glomerulosclerosis $(n=9,11 \%)$, proliferative glomerulonephritis $(n=9,11 \%)$, nephronophthisis $(n=8,10 \%)$, reflux nephropathy $(n=7,9 \%)$, cystinosis $(n=5,6 \%)$, and miscellaneous $(n=10,13 \%)$.

The immunosuppressive treatment used was broadly divided into two groups: high dose prednisolone $\left(30 \mathrm{mg} / \mathrm{m}^{2}\right.$ on alternate days) and azathioprine (regimen 1) or low dose prednisolone $\left(10 \mathrm{mg} / \mathrm{m}^{2}\right.$ on alternate days) and cyclosporin A (regimen 2). There was overlap in steroid dose between the two groups, however: many patients on regimen 1 with live related transplants and stable graft function had their steroid dose reduced, and patients on regimen 2 with poorly functioning grafts had their steroid treatment increased. Furthermore, over the years several children switched regimen. Rejection episodes were managed in the same way for each regimen: methyl prednisolone $600 \mathrm{mg} / \mathrm{m}^{2}$ for three 
consecutive days during the first six weeks post transplant, and oral prednisolone $3 \mathrm{mg} / \mathrm{kg} /$ day for three days after the first six weeks.

The following were obtained from the notes and on examination:

(1) Chronological age at transplantation (years).

(2) Height $(\mathrm{cm})$ at the time of transplantation and subsequently at yearly intervals. For each subject the height standard deviation score $(\mathrm{Ht}$ SDS) was calculated, according to the formula Ht $\operatorname{SDS}=(x-\bar{x}) / S D$, where $\bar{x}$ and SD are age matched population mean height and SD respectively and $\mathrm{x}$ is the subject's height. The height velocity standard deviation score was calculated for each post transplant year in each subject. Normal population data were according to Tanner et al. ${ }^{3}$

(3) Bone age (TW2) and puberty rating ${ }^{4}$ in children over the age of the third centile for appearance of secondary sexual characteristics (boys $>14.0$ years, girls $>13.3$ years).

Eleven children were transplanted before the age of 10 years and were over the age of 14 years. Their calculated glomerular filtration rate $\left(\mathrm{ml} / \mathrm{min} / 1 \cdot 73^{2}\right)^{5}$ was compared at 11 and 14 years of age.

An overnight hormone profile study was performed in 13 boys and four girls who were short ( $<10$ centile), and/or growing poorly (height velocity $<25$ centile) and/or delayed in puberty $(<10$ centile for age). The steroid dose $\left(\mathrm{mg} / \mathrm{m}^{2}\right)$ and the glomerular filtration rate at the time of the study was calculated. ${ }^{5}$ Height velocity $(\mathrm{cm} /$ year) and height velocity SDS were calculated for the six months before the study (table 1). Studies were performed on the day off steroids in all patients except 13,14, 15 and 17. Subjects 1 and 6 were taking daily steroids. Each study commenced at $18 \cdot 00$ hours, when an indwelling cannula was inserted into a forearm vein. Adequacy of sleep was analysed using a portable continuous electroencephalograph (Oxford Medilog System). ${ }^{6}$ Blood samples were taken every 20 minutes from 20.00 hours through to 07.00 hours $(3 \mathrm{ml}$ blood per sample). Plasma was subsequently stored at $-20^{\circ} \mathrm{C}$ until assay. Growth hormone (mU/l), gonadotrophins (luteinising hormone, follicle stimulating hormone, IU/l), and prolactin were measured on each sample and testosterone (nmol/l) and insulin like growth factor $1(\mathrm{U} / \mathrm{ml})$ on intermittent samples through the night. All samples from each profile were batch analysed. Growth hormone was measured by radioimmunoassay using the first International Reference Preparation 66/217, with an intra-assay coefficient of variation of $5.0 \%$ and $2.4 \%$ at 10.8 and $20.4 \mathrm{mU} / \mathrm{l}$ respectively and an interassay coefficient of variation of $10 \%$ at $7.5 \mathrm{mU} / \mathrm{l}$. Gonadotrophins were measured by radioimmunoassay using the first International Reference Preparation of luteinising hormone $68 / 40$ and follicle stimulating hormone $78 / 549$, with an intra-assay coefficient of

Table 1 Patient details at the time of the overnight hormone profiles

\begin{tabular}{|c|c|c|c|c|c|c|c|c|c|c|}
\hline $\begin{array}{l}\text { Patient } \\
\text { No }\end{array}$ & $\begin{array}{l}\text { Alternate } \\
\text { day } \\
\text { steroid } \\
\text { dose } \\
\left(m g / m^{2}\right)\end{array}$ & Cyclosporin A & $\begin{array}{l}\text { Age at } \\
\text { transplant } \\
\text { (years) }\end{array}$ & $\begin{array}{l}\text { Chronological } \\
\text { age } \\
\text { (years) }\end{array}$ & $\begin{array}{l}\text { Bone } \\
\text { age } \\
\text { (years) }\end{array}$ & $\begin{array}{l}\text { Genital } \\
\text { stage }^{4}\end{array}$ & $\begin{array}{l}\text { Height } \\
\text { SDS }\end{array}$ & $\begin{array}{l}\text { Height } \\
\text { velocity } \\
\text { SDS }\end{array}$ & $\begin{array}{l}\text { Height } \\
\text { velocity } \\
\text { (cm/year) }\end{array}$ & $\begin{array}{l}\text { Glomerular } \\
\text { filtration } \\
\text { rate } \\
(\mathrm{ml} / \mathrm{min} \\
\left./ 1 \cdot 73 \mathrm{~m}^{2}\right)\end{array}$ \\
\hline \multicolumn{11}{|c|}{ Girls } \\
\hline 1 & $4 \cdot 4^{*}$ & + & $13 \cdot 1$ & $13 \cdot 3$ & $9 \cdot 6$ & 1 & -4.9 & 0.4 & $6 \cdot 1$ & 80 \\
\hline 3 & $13 \cdot 2$ & + & $11 \cdot 9$ & $14 \cdot 2$ & $12 \cdot 4$ & 3 & $-3 \cdot 5$ & $1 \cdot 2$ & $5 \cdot 9$ & 37 \\
\hline 4 & $22 \cdot 2$ & - & $14 \cdot 7$ & 18.4 & $13 \cdot 8$ & 5 & $-3 \cdot 1$ & - & 0.5 & 58 \\
\hline \multicolumn{11}{|c|}{ Boys } \\
\hline 5 & $4 \cdot 9$ & + & $12 \cdot 6$ & $14 \cdot 4$ & $10 \cdot 4$ & 1 & $-4 \cdot 2$ & $-1 \cdot 9$ & 3.4 & 30 \\
\hline 6 & $3 \cdot 9^{*}$ & + & $14 \cdot 7$ & $15 \cdot 2$ & $14 \cdot 5$ & 3 & $-2 \cdot 4$ & -0.4 & $5 \cdot 1$ & 20 \\
\hline 7 & $8 \cdot 7$ & - & $8 \cdot 8$ & $17 \cdot 5$ & $15 \cdot 3$ & 2 & $-2 \cdot 5$ & 6.0 & $7 \cdot 6$ & 92 \\
\hline 8 & $8 \cdot 8$ & + & $7 \cdot 6$ & $13 \cdot 0$ & $12 \cdot 2$ & 1 & $-2 \cdot 3$ & -0.7 & $4 \cdot 2$ & 33 \\
\hline 9 & $8 \cdot 8$ & - & $8 \cdot 0$ & $14 \cdot 5$ & $12 \cdot 4$ & 2 & $-2 \cdot 3$ & $-2 \cdot 7$ & $1 \cdot 8$ & 76 \\
\hline 11 & $9 \cdot 2$ & + & $12 \cdot 0$ & $13 \cdot 7$ & $12 \cdot 0$ & 1 & $-1 \cdot 4$ & $-1 \cdot 5$ & $3 \cdot 6$ & 64 \\
\hline 12 & $13 \cdot 0$ & - & $7 \cdot 6$ & $14 \cdot 8$ & $13 \cdot 5$ & 2 & $-2 \cdot 4$ & $-1 \cdot 2$ & $4 \cdot 6$ & 84 \\
\hline 13 & $17 \cdot 1$ & + & $11 \cdot 2$ & $13 \cdot 3$ & $11 \cdot 0$ & 1 & $-1 \cdot 9$ & $-1 \cdot 2$ & $3 \cdot 8$ & 24 \\
\hline 14 & $17 \cdot 7$ & - & $11 \cdot 3$ & $12 \cdot 9$ & $9 \cdot 5$ & 1 & $-3 \cdot 0$ & -0.7 & $4 \cdot 6$ & 31 \\
\hline 15 & $23 \cdot 6$ & - & $15 \cdot 0$ & $16 \cdot 9$ & $14 \cdot 5$ & 2 & $-4 \cdot 0$ & $2 \cdot 2$ & $5 \cdot 5$ & 53 \\
\hline 16 & $24 \cdot 6$ & - & $15 \cdot 8$ & $17 \cdot 6$ & $12 \cdot 7$ & 1 & $-6 \cdot 0$ & 2.9 & $1 \cdot 4$ & 50 \\
\hline 17 & $26 \cdot 0$ & - & $12 \cdot 9$ & $15 \cdot 5$ & $15 \cdot 7$ & 3 & -1.4 & -1.9 & $1 \cdot 4$ & 42 \\
\hline
\end{tabular}

*Daily steroid dose. 
1328 Rees, Greene, Adlard, Jones, Haycock, Rigden, Preece, and Chantler

variation of (a) luteinising hormone, $8 \cdot 8 \%$ and $10 \%$ at 2.4 and $15.0 \mathrm{IU} / \mathrm{l}$ and (b) follicle stimulating hormone, $10 \cdot 3 \%$ and $7 \cdot 3 \%$ at 2.8 and $14.9 \mathrm{IU} / \mathrm{l}$ respectively. Prolactin was measured by radioimmunoassay using the first International Reference Preparation of 75/504. Testosterone was measured by standard kit method (Diagnostic Products Corporation). Serum insulin like growth factor 1 was measured by radioimmunoassay after acidethanol extraction. ${ }^{7}$ Antiserum R557A and insulin like growth factor labelled with ${ }^{125} \mathrm{I}^{8}$ were kindly provided by Dr DJ Morrell (Institute of Child Health, London). Intra-assay and interassay coefficient of variation were $<8 \%$ and $<10 \%$ respectively. Values for insulin like growth factor 1 were expressed as potency relative to pooled normal adult human reference serum defined as 1 unit insulin like growth factor $1 / \mathrm{ml}$.

Growth hormone and gonadotrophin hormone peak analysis was performed both visually and using the 'Pulsar' programme, ${ }^{9}$ which was modified locally to include a calculation of area under the curve by summation of trapezoids.

\section{STATISTICAL ANALYSIS}

By definition, the mean SDS of the normal population is zero, and the standard deviation of the distribution is one. Our data were symmetrically distributed; for purposes of statistical comparison with the normal population, the mean and standard deviation of each subgroup of patients was calculated. Comparison of height velocity SDS at various age groupings was by one way analysis of variance. Comparison of glomerular filtration rate at 11 and 14 years of age was by paired $t$ test. Comparison of the association of overnight hormone profile measurements with height velocity, glomerular filtration rate, and steroid dose was by Pearson product moment coefficient. Results are expressed as mean (SE), together with range where appropriate.

\section{Results}

\section{GROWTH DATA}

The mean age (range, years) at transplantation for the boys was $8 \cdot 3(0 \cdot 8-15 \cdot 8)$. They were significantly short at the time of transplantation (height SDS $-2.87(0.26), \mathrm{p}<0.001)$ compared with the normal population. The mean (range) duration of follow up (years) was $3.6(1 \cdot 0-10 \cdot 0)$. At the end of follow up they were significantly short (height SDS $-2 \cdot 24$ $(0.25), \mathrm{p}<0.001)$. In the girls age at transplantation was $9.6(1.7-14.7)$, with a height SDS of $-2 \cdot 10$ $(0 \cdot 24), \mathrm{p}<0 \cdot 001$. Duration of follow up was $3 \cdot 2$ years $(1 \cdot 0-8 \cdot 0)$, with a height SDS at the end of follow up of $-2 \cdot 12(0 \cdot 27), p<0 \cdot 001$.

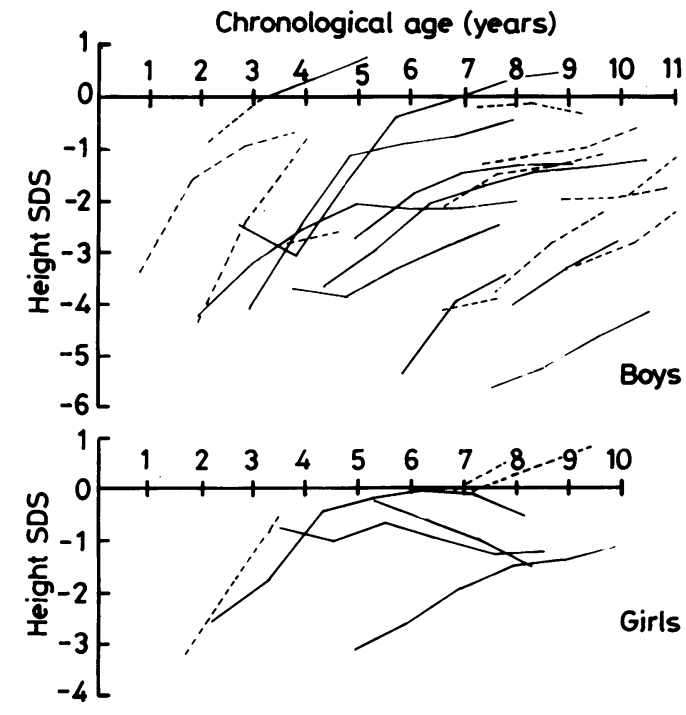

Fig 1 Height SDS at the time of transplantation and at yearly intervals for the 21 boys aged less than 11 years and the seven girls aged less than 10 years at the end of May 1987 ( - - - steroids plus cyclosporin A, — steroids plus azathioprine).

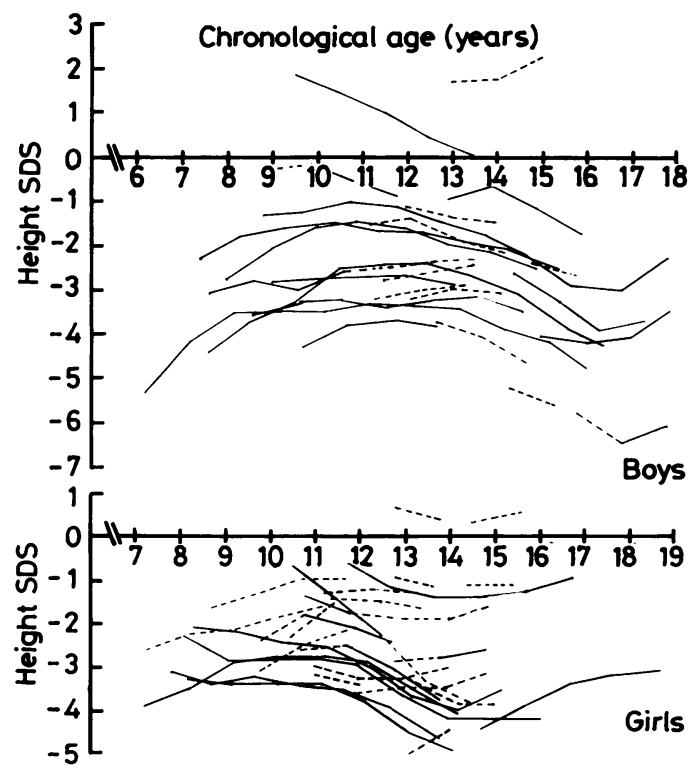

Fig 2 Height SDS at the time of transplantation and at yearly intervals for the 24 boys aged over 11 years and the 27 girls aged over 10 years at the end of May 1987 (- - - steroids plus cyclosporin A, - steroids plus azathioprine). 


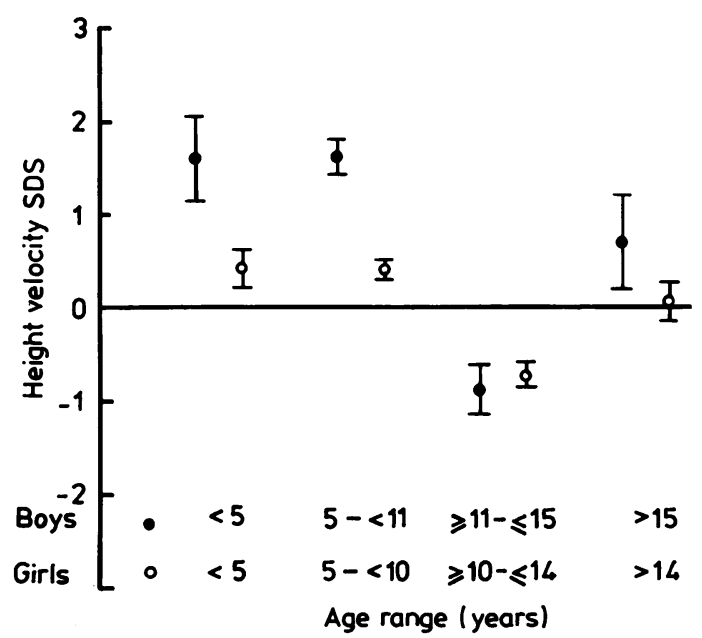

Fig 3 Mean (SE) height velocity SDS at different age ranges post renal transplantation.

Height SDS at the time of transplantation and at yearly intervals thereafter are shown for the prepubertal children in fig 1 , and for the older children in fig 2. An arbitrary division at the age of 11 years in the boys and 10 years in the girls at the time of the last examination was chosen to examine the effect of puberty. In both boys and girls after the initial improvement in height SDS there was a subsequent fall at the time of the expected pubertal growth spurt, with the beginning of a recovery in some adolescents near adulthood. There appeared to be no difference in the growth patterns between immunosuppressive regimens 1 and 2 .

To examine the effect of puberty on growth more closely, both sexes were subdivided into the following chronological age groups (years): boys, $<5$, $5-<11, \geqslant 11-\leqslant 15$, and $>15$; girls, $<5,5-<10$, $\geqslant 10-\leqslant 14,>14$. Height velocity SDS at yearly intervals from the time of transplantation was measured in each subject and the mean for all subjects calculated in each age grouping. The results are shown in fig 3 . In the boys height velocity SDS at yearly intervals was significantly greater compared with the normal population in age group $<5(1.58$ $(0.46), \mathrm{p}<0.001)$ and $5-<11(1.58(0.22), \mathrm{p}<0.001)$; at age $11-\leqslant 15$ it was significantly less $(-0 \cdot 88(0 \cdot 26)$, $\mathrm{p}<0.001)$; after 15 there was no significant difference $(0.68(0.52))$. The height velocity SDS in the $\geqslant 11-\leqslant 15$ age grouping was significantly lower compared with the other age groups $(F=18 \cdot 6$, df between groups was 3 and within groups was 162 , $\mathrm{p}<0.01)$. A similar picture was seen in the girls with a high height velocity SDS compared with the normal population in age groups $<5(0 \cdot 41(0 \cdot 20)$, $\mathrm{p}<0.05)$ and $5-<10(0.40(0.10), \mathrm{p}<0.001), \mathrm{a}$ decrease in age group $\geqslant 10-\leqslant 14(-0.74(0.12)$, $\mathrm{p}<0.001)$ and no significant difference in girls $>14$ $(0.04(0.23))$. The height velocity SDS in the $\geqslant 10-\leqslant 14$ age group was significantly lower compared with the other age groups $(F=8 \cdot 82$, df between groups was 3 and within groups was 105 , $\mathrm{p}<0.01)$. There was no significant difference between the glomerular filtration rate $\left(\mathrm{ml} / \mathrm{min} / 1.73 \mathrm{~m}^{2}\right)$ at age 11 years $(60(3 \cdot 6))$ and at age 14 years $(65(5 \cdot 5))$, and no correlation between height velocity and glomerular filtration rate in the children undergoing overnight profiles.

Ten of the 16 boys over the age of 14.0 years and six of the 19 girls over the age of 13.3 years were below the third centile for pubertal development. ${ }^{4}$ Bone age compared with chronological age (both in years) in these subjects was delayed in both sexes; mean bone age minus mean chronological age (range): boys $-2 \cdot 0(-4.0$ to $0 \cdot 0)$, girls $-1 \cdot 1(-4.8$ to $1 \cdot 2)$.

\section{OVERNIGHT HORMONE PROFILES}

Clinical details of the subjects in whom overnight profiles were performed are given in table 1 . All subjects slept through the study with normal patterns on electroencephalography. ${ }^{6}$ Data of hormone profiles from a control group were lacking. Various studies over the last 15 years, however, have suggested an appreciable increase in pulsatility of growth hormone and gonadotrophins during the age range associated with normal puberty. ${ }^{10-15}$ Visual comparison with these documented profiles and profile analysis suggested that one girl (patient 4) and seven boys (patients 5, 9, 11, 12,13, 16, and 17) had decreased secretion of growth hormone (table 2). There was a significant correlation between the height velocity over the previous six months (cm/year) and area of growth hormone under the curve $(\mathrm{mU} / \mathrm{l} / \mathrm{hour})(\mathrm{r}=0.60, \mathrm{p}=0.01)$, the mean growth hormone concentration $(r=0 \cdot 60, p=0 \cdot 01)$, and the growth hormone mean peak amplitude $(r=0 \cdot 80, p=0 \cdot 0001)$. There was no correlation between either the steroid dose $\left(\mathrm{mg} / \mathrm{m}^{2}\right)$ or the glomerular filtration rate and growth velocity or any parameters of growth hormone. All concentrations of insulin like growth factor 1 were within normal limits for age and sex. Secretion of luteinising hormone was low in two girls (patients 1 and 2) and six boys (patients $9,12,13,15,16$, and 17), with reduced pulsatility in one other boy (10). There was no correlation between the area of luteinising hormone under the curve (IU/1/hour), mean luteinising hormone concentration or mean peak amplitude of luteinising hormone and either height velocity, glomerular filtration rate, steroid dose, or any parameters of growth hormone. Follicle stimulating 
1330 Rees, Greene, Adlard, Jones, Haycock, Rigden, Preece, and Chantler

Table 2 Overnight hormone profile analysis for growth hormone and insulin like growth factor 1 concentrations in 17 adolescents with renal transplants

\begin{tabular}{|c|c|c|c|c|c|}
\hline \multirow{2}{*}{$\begin{array}{l}\text { Patient } \\
\text { No }\end{array}$} & \multirow{2}{*}{$\begin{array}{l}\text { Area } \\
\text { under curve } \\
\text { (mU/l/hour) }\end{array}$} & \multirow{2}{*}{$\begin{array}{l}\text { Mean growth } \\
\text { hormone } \\
(\mathrm{mU} / \mathrm{l})\end{array}$} & \multicolumn{2}{|c|}{ Pulses } & \multirow{2}{*}{$\begin{array}{l}\text { Mean insulin } \\
\text { like growth } \\
\text { factor } 1 \\
(\mathrm{U} / \mathrm{ml})\end{array}$} \\
\hline & & & No & $\begin{array}{l}\text { Mean amplitude } \\
(m U / l)\end{array}$ & \\
\hline \multicolumn{6}{|c|}{ Girls } \\
\hline 1 & 1154 & $18 \cdot 9$ & 5 & $43 \cdot 2$ & $1 \cdot 7$ \\
\hline 2 & 697 & $11 \cdot 4$ & 5 & $16 \cdot 6$ & $2 \cdot 1$ \\
\hline 4 & 90 & $1 \cdot 6$ & 3 & $2 \cdot 2$ & 1.9 \\
\hline \multicolumn{6}{|c|}{ Boys } \\
\hline 5 & 226 & $3 \cdot 8$ & 3 & $8 \cdot 6$ & $1 \cdot 1$ \\
\hline 6 & 2606 & 41.9 & 3 & $50 \cdot 0$ & $1 \cdot 5$ \\
\hline 7 & 1329 & $20 \cdot 2$ & 3 & $47 \cdot 7$ & $1 \cdot 6$ \\
\hline 8 & 1156 & 19.0 & 4 & $30 \cdot 5$ & 1.9 \\
\hline 9 & 351 & $5 \cdot 4$ & 5 & $12 \cdot 9$ & $2 \cdot 2$ \\
\hline 10 & 469 & $7 \cdot 8$ & 3 & $17 \cdot 7$ & $1 \cdot 8$ \\
\hline 12 & 185 & $3 \cdot 4$ & 3 & $10 \cdot 6$ & 1.4 \\
\hline 13 & 212 & $3 \cdot 5$ & 2 & $9 \cdot 0$ & $1 \cdot 3$ \\
\hline 14 & 862 & $14 \cdot 1$ & 2 & $27 \cdot 8$ & 1.9 \\
\hline 15 & 999 & $17 \cdot 2$ & 4 & 33.7 & $3 \cdot 4$ \\
\hline 16 & 107 & $1 \cdot 8$ & 1 & $8 \cdot 6$ & $1 \cdot 3$ \\
\hline 17 & 331 & $5 \cdot 5$ & 1 & $16 \cdot 7$ & $2 \cdot 0$ \\
\hline
\end{tabular}

hormone concentrations was low, with reduced pulsatility in one girl (patient 2) and nine boys (patients $5,7,8,9,10,12,13,14$, and 16). Concentrations of testosterone were below $3 \cdot 0$ $\mathrm{nmol} / 1$ in eight boys. Testosterone correlated significantly with the area of growth hormone under the curve $(r=0.83, p=0.0004)$, mean growth hormone concentration $(r=0.83, p=0 \cdot 0005)$, and mean peak amplitude of growth hormone $(r=0.75$, $p=0 \cdot 003$ ). Testosterone was only weakly correlated with the area of luteinising hormone under the curve $(r=0.50, p=0 \cdot 08)$, mean luteinising hormone concentration $(r=0 \cdot 50, p=0 \cdot 08)$, and mean peak amplitude of luteinising hormone $(r=0.60, p=0.035)$ but not with luteinising hormone pulse number.
There was no correlation between testosterone and height velocity or glomerular filtration rate. Prolactin secretion was within normal limits for all subjects (table 3). Examples of the overnight profiles from two boys of similar age and both in mid puberty are shown in fig 4 . Patient 6 was growing at a rate of $5 \cdot 1$ $\mathrm{cm} /$ year and had normal growth hormone and luteinising hormone pulsatility, whereas patient 17 , who was growing at only $1.4 \mathrm{~cm} /$ year had pronounced blunting of growth hormone and gonadotrophin secretion.

\section{Discussion}

We have shown that acceleration of growth can be

Table 3 Overnight profile analysis for luteinsing hormone, follicle stimulating hormone, testosterone, and prolactin. Results are mean (range)

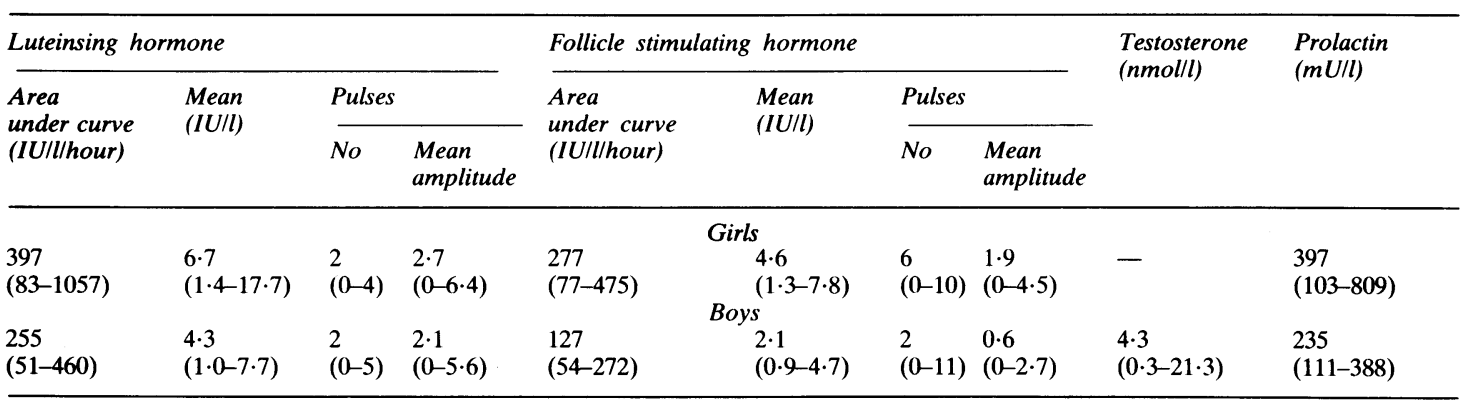



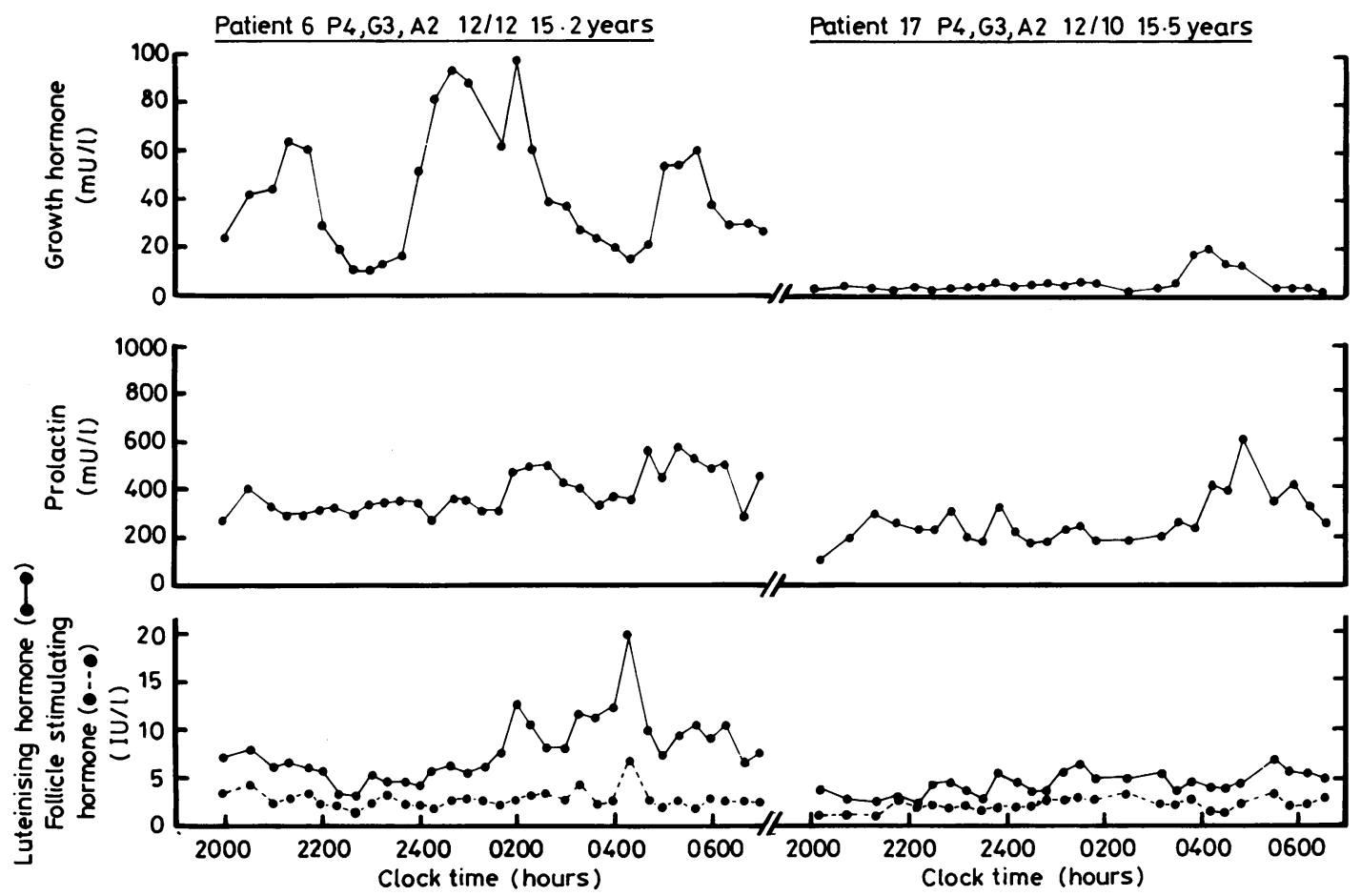

Fig 4 Overnight hormone profiles in a boy who is growing satisfactorily (patient 6) and in a boy who is growing poorly (patient 17). $P=$ pubic hair stage, $G=$ genital stage, $A=$ axillary hair stage, $-/-=$ testicular volumes. ${ }^{4}$

achieved in prepubertal children after renal transplantation, as suggested previously from our own ${ }^{16}$ and other centres. ${ }^{17} 18$ Recent studies have suggested better growth rates in patients taking cyclosporin A and low dose steroids than in those receiving azathioprine and high dose steroids..$^{1920}$ Multiple confounding factors, however, such as heterogeneity of diagnoses, age at onset of chronic renal failure, age at transplantation, number of rejection episodes, graft function, bone age, the onset of puberty, live related or cadaver donor, and in our patients alteration of the immunosuppressive regimen over the years, makes us reluctant to investigate the question with our data. Visual inspection of the growth patterns does not, however, show any obvious difference, and there is no correlation between growth rates and steroid dose in the adolescents undergoing overnight profiles.

It is clear that after the initial acceleration prepubertally, growth velocity declines in early adolescence and there is a delay in both boys and girls in the appearance of secondary sexual characteristics. Poor growth during puberty has been reported previously. ${ }^{21}$ Deteriorating allograft func- tion did not contribute to this declining growth rate in our adolescents. The onset of normal puberty is associated with increasing pulsatility of both growth hormone and gonadotrophin secretion. ${ }^{10-15}$ Appreciable blunting of both growth hormone and gonadotrophin secretion was seen in a high proportion of our subjects, who were studied because of short stature or delayed puberty or both. Concentrations of insulin like growth factor 1 were normal, but their interpretation in renal disease is unclear. ${ }^{22}$ Concentrations of plasma testosterone were low in over half the boys studied. There was no evidence that prolactin (which at high levels has been reported to decrease luteinising hormone pulsatility in $\mathrm{men}^{23}$ ) was responsible, as values were within normal limits. ${ }^{24}$

Abnormalities of pubertal growth and hormone secretion do not appear to be a feature of chronic renal failure itself. ${ }^{22} 25-27$ We have observed, however, blunting of the overnight secretion of growth hormone and gonadotrophins in boys receiving long term steroid treatment for steroid sensitive nephrotic syndrome. ${ }^{2}$ This was also associated with the delayed onset of puberty. It is likely, therefore, that long 


\section{Rees, Greene, Adlard, Jones, Haycock, Rigden, Preece, and Chantler}

term steroid treatment interferes with the onset and progression of puberty and the pubertal growth spurt. The results of the overnight hormone profiles indicated that the interference is central, at the hypothalamic-pituitary end of the axis. The effect this may have on the final height of children who have had renal transplants remains unknown; it is possible that the benefits of the initial good response in growth is lost to the steroid effects on the pubertal growth spurt. The picture of delayed puberty, however, has severe implications in the clinical management after renal transplantation.

All the transplant patients received long term alternate day steroid treatment as part of their immunosuppressive regimen, although as discussed the dose of steroids varies considerably. Given our findings it may be advisable to attempt to reduce the steroid treatment to absolute minimum in those children approaching the expected onset of puberty. Indeed, in children with longstanding transplants and stable function, who are showing a declining growth rate, it may be advisable to use an immunosuppressive regimen that excludes steroids. Alternatively, it may be appropriate to attempt to improve growth with low dose anabolic steroid treatment or with growth hormone itself.

This work was supported by the Children's Nationwide Medical Research Fund. SAG is supported by the Wellcome Trust, PA by grants from Serono Laboratories (UK) and the Child Growth Foundation, and JJ by a grant from the Adint Trust. We thank Dr Charles Buchanan for analysis of insulin like growth factor 1, Miss G Wilson and Mrs J Jenkins for the recordings of electroencephalography, and the sister and nursing staff of Peter Bishop metabolic ward.

\section{References}

${ }^{1}$ European Dialysis Transplant Association. Combined report on regular dialysis and transplantation of children in Europe. Basel: Hospal Ltd, 1985:82-8.

2 Rees L, Greene SA, Adlard P, et al. Growth and endocrine function in steroid sensitive nephrotic syndrome. Arch Dis Child 1988;63:484-90.

3 Tanner JM, Whitehouse RH, Takaishi M. Standards from birth to maturity for height, weight, height velocity and weight velocity: British children, 1965. Part II. Arch Dis Child 1966;41: 613-35.

${ }^{4}$ Tanner JM. Growth at adolescence. 2nd ed. Oxford: Blackwell Scientific Publications, 1962.

5 Morris MC, Allanby CW, Toseland P, et al. Evaluation of a height/plasma creatinine formula in the measurement of glomerular filtration rate. Arch Dis Child 1982;57:611-4.

${ }^{6}$ Rechtshaffen A, Kales A. A manual of standardised terminology, techniques and scoring system for sleep stages. Bethesda, Maryland: National Institutes of Health Publication No 204, 1971 .

${ }^{7}$ Morrell DJ, Ray KP, Holder AT, et al. Somatomedin C/insulinlike growth factor I: simplified purification procedure and biological activities of the purified growth factor. $J$ Endocrinol 1986;110:151-8.
${ }^{8}$ Daughaday WH, Mariz IK, Blethen SL. Inhibition of access of bound somatomedin to membrane receptor and immunobinding sites: a comparison of radioreceptor and radioimmunoassay of somatomedin in native and acid-ethanol-extracted serum. J Clin Endocrinol Metab 1980;51:781-8.

9 Merriam GR, Wachter KW. Algorithms for the study of episodic hormone secretion. Am J Physiol 1982;243:E310-8.

${ }^{10}$ Finkelstein JW, Roffwarg HP, Boyar RM, et al. Age related change in the 24 hour spontaneous secretion of growth hormone. $J$ Clin Endocrinol Metab 1972;35:665-70.

"1 Plotnick LP, Thompson RG, Kowarski AA, et al. Circadian variation of integrated concentration of growth hormone in children and adults. J Clin Endocrinol Metab 1975;40:240-5.

12 Zadik Z, Chalew SA, McCarter RJ Jr, et al. The influence of age on the 24-hour integrated concentration of growth hormone in normal individuals. J Clin Endocrinol Metab 1985;60:513-6.

${ }^{13}$ Mauras N, Blizzard RM, Link K, et al. Augmentation of growth hormone secretion during puberty: evidence for a pulse amplitude-modulated phenomenon. J Clin Endocrinol Metab 1987;64:596-601.

${ }^{14}$ Lee PA, Plotnick LP, Steele RE, et al. Integrated concentrations of luteinising hormone and puberty. J Clin Endocrinol Metab 1976;43:168-72.

15 Lee PA, Plotnick LP, Migeon CJ, et al. Integrated concentrations of follicle stimulating hormone and puberty. J Clin Endocrinol Metab 1978;46:488-90.

${ }^{16}$ Bosque M, Munian A, Haycock GB, Chantler C. Growth after renal transplants. Arch Dis Child 1983;58:110-4.

17 Hodson EM, Najarian JS, Kjellstrand CM, et al. Renal transplantation in children ages 1 to 5 years. Pediatrics 1978;61: 458-64.

18 Ingelfinger JR, Grupe WE, Harmon WE, et al. Growth acceleration following renal transplantation in children less than 7 years of age. Pediatrics 1981;68:255-9.

19 Brodehl J, Offner G, Hoyer PF, et al. Cyclosporin in pediatric transplantation and its effect on post transplantation growth Nephron 1986;44:26-31.

${ }^{20}$ Offner G, Hoyer PF, Juppner H, et al. Somatic growth after kidney transplantation. Beneficial effect of cyclosporine in comparison with conventional immunosuppression. Am J Dis Child 1987;141:541-6.

21 van Diemen-Steenvoorde R, Donckerwolcke RA, Brackel H, et al. Growth and sexual maturation in children after kidney transplantation. J Pediatr 1987;110:351-6.

22 Rees L, Chantler C. Hormonal alterations that affect the growth of children with chronic renal failure. Proceedings of the tenth International Congress of Nephrology 1987 (in press).

${ }^{23}$ Winters SJ, Bardin CW. Altered pulsatile secretion of luteinising hormone in hypogonadal men with hyperprolactinaemia. Clin Endocrinol (Oxf) 1984;21:257-63.

${ }^{24}$ Finkelstein JW, Kapen S, Weitzman ED, et al. Twenty-fourhour plasma prolactin patterns in prepubertal and adolescent boys. J Clin Endocrinol Metab 1978;47:1123-8.

${ }^{25}$ Rees L, Rigden SPA, Chantler C, Haycock GB. Growth and methods of improving growth in chronic renal failure managed conservatively. Pediatric and Adolescent Endocrinology. Basel: $S$ Karger AG (in press).

${ }^{26}$ Kleinknecht C, Broyer M, Huot D, et al. Growth and development of non-dialysed children with chronic renal failure. Kidney Int 1983;24:S40-7.

27 Rizzoni G, Basso T, Setari M. Growth in children with chronic renal failure on conservative treatment. Kidney Int 1984;26: 52-8.

Correspondence to Dr L Rees, University Department of Paediatrics, Guy's Tower (Floor 12), Guy's Hospital, London Bridge, London SE1 9RT.

Accepted 6 May 1988 